\title{
CORONELISMO ELETRÔNICO: relações assimétricas de poder no campo midiático paranaense
}

\author{
André Kron Marques Zapani ${ }^{1}$
}

\begin{abstract}
RESUMO: Este artigo visa analisar o conceito histórico-social seminal do coronelismo (Victor Nunes Leal), todavia em uma perspectiva comunicacional, tomando por base as convergentes e indissociáveis relações de poder e de hegemonia entre integrantes da sociedade política e agentes da sociedade civil paranaense, a partir da metade do século passado. A ressignificação desse conceito, Coronelismo Eletrônico (Suzy dos Santos e Sérgio Cappareli), configura um recente e difuso quadro de arranjos de empoderamento que tem nas práticas comunicacionais e, sobretudo, na disputa por concessões radiofônicas grandes elementos de barganha política. Cabe destacar, também, que esse "novo" protagonista sócio-político tem obtido projeções de direção e dominação nos campos midiático e político paranaense, em função, também, de um destacado e imbricado arranjo familial, a ser analisado neste artigo.
\end{abstract}

Palavras-chave: Hegemonia. Poder. Campo Midiático. Coronelismo Eletrônico. Família.

\section{ELECTRONIC CORONELISM: Asymmetric relations of power in the media field of}

\section{Paraná}

\begin{abstract}
This article aims to analyze the seminal historical-social concept of coronelism (Victor Nunes Leal), however in a communication perspective, based on the convergent and inseparable power relations and hegemony between members of the political society and agents of the civil society of Paraná, The last half century. The resignification of this concept, Electronic Colonelism (Suzy dos Santos and Sérgio Cappareli), constitutes a recent and diffuse framework of arrangements of empowerment that has in the communication practices and, mainly, in the dispute for radio concessions, great elements of political bargaining. It should also be noted that this "new" sociopolitical protagonist has obtained projections of direction and domination in the media and political fields of Paraná, as well as a prominent and overlapping family arrangement, to be analyzed in this article.
\end{abstract}

Keywords: Hegemony. Power. Media Field. Electronic Coronelism. Family

- Enviado em 01/05/2017

- Aprovado em 17/05/2017

1 Doutorando do Programa de Pós-Graduação de Sociologia da Universidade Federal do Paraná. Uma versão preliminar desse texto foi apresentada no VIII Seminário Nacional de Sociologia e Política realizado de 17 a 19 de maio de 2017 na UFPR E-mail: andrekron@gmail.com 


\section{AS ORIGENS DO PROCESSO HISTÓRICO-SOCIOLÓGICO}

A gênese da formação dos impérios midiáticos é indissociável à formação histórica e política brasileira e nos remete a uma regressão temporal original à época colonial, se desenvolve por toda monarquia e se consolida na república nova em convergência com outros campos de poder. Sofreu influências de diversos ciclos econômicos que se estendeu pelo extrativismo, pela agropecuária, pela mineração, pela industrialização e pelas relações comerciais de bens e serviços, tanto em áreas rurais latifundiárias quanto em ambientes urbanos, empregando mão-de-obra escrava, livre e assalariada. Cada região do país desenvolveu suas idiossincrasias na consolidação dos grupos midiáticos, seus personagens com seus respectivos capitais simbólicos, seus grupos hegemônicos e contrahegemônicos, suas estratégias para a manutenção e subversão do status quo vigente, mas também desenvolveu predicados que tiveram abrangência nacional que se arraigaram até hoje.

Ressalta-se a interpolada relação de formação e de consolidação do campo midiático contemporâneo com o campo político e da relevante proximidade com o econômico, bem como as relações conexas e quase indissociáveis de clientelismo, de concentração de poder, de redes familiais, de poder local e de parcerias público-privada nesta convergência de campos, que são conceitos sociológicos e de inserção histórica vital para a sobrevivência, para a interpretação e, sobretudo, para a ressignificação do campo político e midiático nacional da contemporaneidade.

Esta paulatina aglutinação de poderes em prol de personagens com vínculos diretos ou indiretos com a órbita política, que promoveu a consolidação difusa das relações pessoas-estatais atuais, necessita de um breve e introdutório regresso histórico, iniciando-se pelo pioneiro BrasilColônia, mas sempre se fazendo analogia com o quadro presente. Este levantamento temporal se faz necessário a fim de se compreender como foram consolidadas as alianças familiais em seu bojo entre o poder central de outrora (o executivo contemporâneo) e os notórios precursores de concessões: os concessionários de lotes de terra do século XVI e XVII (capitães donatários e sesmeiros) e os coronéis latifundiários da República Velha (empresários do ramo da comunicação do século XX e XXI) - poder local. 
Os donatários das capitanias hereditárias eram súditos, quase que na íntegra, da Coroa real e pertenciam, em geral, à pequena nobreza, a nobreza da "terra" ${ }^{2}$, que junta ao povo português formaram a genealogia brasileira. Esse grupo era compostos por militares, homens de negócio, burocratas, nobres da terra, magistrados, escrivães, bacharéis, ordenanças e eram escolhidos como receptores desses lotes de terra pelo poder financeiro, pela representatividade social e/ou pela proximidade com a nobreza real, tendo algum capital social, político ou econômico a compartilhar com a fausta corte lusitana.

Doze dos treze donatários agraciados, conforme consta em suas cartas de doação, "eram inequivocamente fidalgos da Casa Real" (COSENTINO, 2015, p.537), o que atestavam suas importâncias sociais e as suas inserções no estrato da realeza ${ }^{3}$.

Estes súditos possuíam o direito de usufruir das propriedades, do comando militar, de exercer a justiça, de arrecadar taxas e administrar. Era esperado, o que não se consolidou, que estes nobres possuíssem habilidades de investimento, de administração, de bom relacionamento com os indígenas, além de prover uma boa defesa militar às novas terras. Quanto a estas, o donatário deveria distribuí-las gratuitamente em sesmarias ${ }^{4}$ aos que tivessem condições de cultivá-las, e reservar determinada área (20\%) para uso seu e dos futuros titulares da donataria (80\%).

Esta subdivisão fundiária de cunho político e social teve sua distribuição feita de maneira direcionada e aleatória, principalmente quanto à dimensão dos lotes (a próspera região nordeste, de maioria de concessões da nobreza lusitana, era maior que a sulina). Constituiu-se no principal e pioneiro meio de povoar a nova terra, bem como promover uma proteção da costa contra às investidas francesas no litoral nacional, além de ser a gênese dos latifúndios, tornando-se, em seguida, em vilas e em municípios, o locus de atuação do mandonismo, do poderio local privado e das forças de sustentação dos políticos dominantes.

2 Aprofundamento desta estratificação social em Oliveira (2012)

${ }^{3}$ Com relação às capitanias e às origens de seus administradores, ver Zapani (2011)

${ }^{4}$ Lotes de terra de dimensões diversas concedidos pela Coroa Real a terceiros. Ver em MERÊA (1924) e LIMA (1988). Com relação às sesmarias no atual estado do Paraná, a obra de Marina Ritter - As sesmarias no Paraná no século XVIII. Curitiba: IGHPR, 1980, realizou uma ampla cartografia da genealogia familial dos nobres concessionários latifundiários, suas distribuições geográficas e seus evidentes poderes locais atuais. 
Na realidade, as sesmarias eram doadas aos poderosos que alegassem possuir meios para explorá-las e que pudessem fundar engenhos. Como observa Oliveira Vianna, em seus pedidos, os requerentes de sesmarias faziam constar, em consonância com os pensamentos da Coroa, que eram homens de posses. Cada um dos pretendentes se justificava dizendo que "[sic] hé home de muita posse e família" ou que "hé home de posse assim de gente como de criasões q'ha um morador san pertensentes", ou que "tem muita abriqua de guado de toda sorte e escravos como qualquer morador" (1933, p.56-57).

Esta forma de concessão latifundiária, oficialmente extinta em $1850^{5}$, proporcionou o surgimento de um novo protagonista - o coronel - arquétipo de uma ressignificada figura dominante e atuante originalmente em vilas afastadas dos centros urbanos, configurando-se em uma nova "nobreza" pertencente integralmente à prosopografia social e política brasileira.

O coronel é personagem fundamental para se analisar as relações de poder atual que inicialmente foram econômicas, mas, com o transcorrer temporal, tornaram-se veementemente social e político. Além disso, retrocede-se a ele a fim de se entender as relações de clientelismo na administração da res publica bem como evidenciar a manutenção perene de antigas e tradicionais estruturas oligárquicas de poder em diversas searas da sociedade civil e política brasileira. 0 coronel é figura fulcral no entendimento das rotinas tanto na grande quanto na pequena política nacional, mas têm suas idiossincrasias diversas em cada região do país.

Com o intuito de se aprofundar nesta categoria histórico-sociológico, mote desta pesquisa, este autor crê na necessidade de se traçar breves esboços de um ethos coronelístico, obviamente avesso à bricolagem de diversos perfis díspares existentes de acordo com a região de atuação, a fim de integrá-lo, seguidamente, ao campo midiático, bem como crê na necessidade de se entender como ocorreu o processo panorâmico de "surgimento" desta figura empírica e sua trajetória social na espacialidade e na temporalidade.

\footnotetext{
${ }^{5}$ Segundo a Lei de Terras, a propriedade da terra deixou de integrar o patrimônio pessoal do Imperador, que a distribuía segundo o prestígio social do beneficiário, passava a ser considerada tão-somente uma mercadoria, a ser adquirida na proporção do poder econômico de seu comprador, favorecendo pequenos agricultores e posseiros. (JUNQUEIRA, 1942)
} 


\section{A FIGURA DOMINANTE}

Após a abdicação e o regresso de D. Pedro I para Portugal, em 1831, o Brasil Colônia, segundo a Constituição de 1824, ingressou em um sistema regencial (1831-1845) e passou a ser administrado inicialmente por uma trina provisória, haja vista que o sucessor do então rei era apenas uma criança de cinco anos de idade. Em resposta às agitações militares e populares ocorridas neste tumultuado período histórico, criou-se, em 1831, a Guarda Nacional, semelhante ao modelo francês com raízes populares, mas de timbre aristocrático com traços plebeus e democráticos ${ }^{6}$

Na sua estrutura, a Guarda Nacional era composta, entre outros cargos, por capitães, majores e tenentes-coronéis que seriam designados de forma representativa por meio de escrutínio secreto e por maioria absoluta simples. No entanto, em 1850, a lei no 602, de 19 de setembro, reformulou a Guarda Nacional ${ }^{7}$, extinguindo o processo eleitoral direto para ocupação dos postos de oficiais, proporcionando alterações consideráveis em sua organização. Entre elas, pode-se destacar o novo processo de ocupação de altos cargos que, segundo o novo dispositivo legal "Todos oficiais da Guarda Nacional terão patentes, e por elas pagarão [grifo meu] de novo direito além do Sello, a quantia equivalente a um mês do soldo que competir aos oficiais de linha de iguais postos" (BRASIL, 1850, Art. 57).

Esta instituição teve sua extinção decreta apenas em 1918, já na República Nova. No entanto, foi no transcurso de sua existência que apareceu e, principalmente, se consolidou a figura do coronel, em quase todos os municípios. Mesmo com o fim da Guarda, os coronéis continuaram coronéis, em uma forma tácita de poder e de respeito pelos seus seguidores, independente de amparo legal.

No entanto, o título de coronel era ofuscado por outras categorias de nobreza (duque, marquês, visconde, conde e barão), além dos títulos acadêmicos de doutor (médico) e bacharel (advogado) e engenheiro. Segundo Pang (1979, p.26), como a média e a baixa nobreza nacional não tinham o capital econômico ou acadêmico suficiente para obtê-los, o posto militar era o título

\footnotetext{
${ }^{6}$ Ver Brasil (1831)

${ }^{7}$ Aprofundamento da temática na obra “Milícia Cidadã: a Guarda Nacional de 1831 a 1850", de Jeanne Castro.
} 
mais acessível, tomando- o um contexto jocoso ou vulgar perante a sociedade real, semelhante a um novo-rico.

A procura pelo status de nobreza não se restringiu apenas à aristocracia inculta do sertão, as pessoas de boa família, as de formação acadêmica e os proprietários de engenho de açúcar também tinham o interesse.

O importante que deve ser destacado nesta busca por títulos honoríficos é que os políticos que postulavam cargos nas esferas estadual ou nacional demandavam de apoio dos mandões locais a fim de aumentar seu curral eleitoral. Sendo assim, estes parlamentares ou postulantes ao cargo solicitavam apoio de representantes do executivo (entre eles o ministro da Justiça responsável direto pela Guarda Nacional) que se utilizam legalmente da distribuição reembolsável de títulos de coronel em troca do direcionamento do voto ao seu candidato. Utilizavam-se diversas práticas persuasivas físicas ou psicológicas, caracterizando relações de clientelismo público-privado e o comércio de concessões públicas (processo semelhante às concessões radiofônicas atuais).

A patente de coronel deixou, paulatinamente, durante o século XIX, de se relacionar com o exercício estrito legal e com as atribuições militares ou policiais e passou a ter um componente de projeção de poder, de dominância, de deferência pública, de distinção aos chefes políticos locais e de arbitragem social com ululante liderança política, principalmente durante o período republicano nas diversas regiões do país.

Incorrem-se em corriqueiras e contumazes interpretações inadequadas quando se tenta criar uma relação exclusiva do coronel com o latifúndio e com as relações fundiárias (Carone,1971). Esta suposição é errônea. Trazendo à tona diversas literaturas do tema ${ }^{8}$, chega-se à conclusão que este personagem pode se adaptar em diversos estratos sociais, tais como Chaul (1998) mostram que, em Goiás, o coronel estava desvinculado da posse de terra e se destacava não por suas posses, mas pela capacidade de articular o mando com a violência.

André Heráclito do Rêgo (2008) comenta que esta figura nem sempre se confunde com a grande propriedade ou o grande comerciante, mas quando estas duas condições se reuniam o

\footnotetext{
${ }^{8}$ Com relação à espacialidade de atuação do coronel, díspares e amplas são as abordagens sociológicas e históricas. Este assunto em específico será abordado em outro artigo.
} 
coronel era muito mais poderoso. Eul-Soo Pang (op. cit., p.57-58) chega até a categorizar os coronéis em quatro divisões ocupacionais: proprietário de terras, comerciante, industrial e padre.

Victor Nunes Leal em sua obra pioneira e original, de 1949, sobre o conceito, já destacara:

Os chefes políticos municipais nem sempre são os autênticos coronéis [grifo meu]. A maior difusão do ensino superior no Brasil espalhou por toda parte médicos e advogados, cuja ilustração relativa, se reunida a qualidades de comando e dedicação, os habilitava à chefia [...] Qualquer que seja, entretanto, o chefe municipal, o elemento primário desse tipo de liderança é o coronel, que comanda discricionariamente um lote considerado de votos de cabresto" (2012, p.44-45)

Seguindo neste ínterim, outro exemplo empírico, mas de abrangência pontual, de que os coronéis não eram exclusivamente os opulentos e brancos senhores de terra, Maria Janotti (1981), na sua obra "O coronelismo: uma política de compromissos", discorre sobre a rica matriarca maranhense de extensa família, Ana Jânsen Pereira. Chefe da facção liberal da Província de São Luís que, durante a Guerra da Balaiada (1837-1840), financiou a preparação militar do Batalhão da Guarda Nacional local, que fora comandado pelo Tenente-Coronel Izidoro Jânsen Pereira, seu filho.

“Mas o verdadeiro coronel era aquele que possuindo ou não o título, assim era considerado por sua gente, por seus aliados e mesmo por seus adversários e inimigos" (RÊGO, 2008, p.68). Os padres, os párocos ou os "messias" também têm grande destaque na ocupação destes espaços sociais de dominação ${ }^{9}$.

\section{O PROTAGONISMO E AS RELAÇÕES DE PERTENCIMENTO}

Após esse sucinto mapeamento deste multifacetado personagem que orbita nos campos das ciências sociais e das humanas e, sobretudo, nas suas sobreposições, é importante inseri-lo com pertinência em seu contexto sociológico mais stricto (o coronelismo), em seus arranjos

\footnotetext{
${ }^{9}$ Ver casos de Antônio Conselheiro, líder da Guerra de Canudos (1896-1897), os "monges" da Guerra do Contestado (1912-1916), bem como a clássica e polêmica figura de Cícero Romão Batista, o Padre Cícero
} 
sistêmicos regionais e em suas interpretações empíricas e dialéticas, a fim de interpretá-lo e situálo contemporaneamente, bem como tentar ressignificá-lo, no campo midiático.

É inviável e até ilegítimo não se iniciar este percurso de pesquisa pela origem, pelo seminal clássico de Victor Nunes Leal, “Coronelismo, enxada e voto: o município e o regime representativo no Brasil" que promoveu no meio acadêmico diversas interpretações e releituras e que, segundo José Murilo de Carvalho, endossado pelo autor, fez surgir imprecisões e inconsistência no uso de conceitos da obra de Leal ${ }^{10}$.

Evidencia-se que o coronelismo é elemento essencial para compreendermos a estruturação política e social nacional de hoje. Além de ser um sistema [grifo meu] de que o coronel é integrante e personagem sine qua non, ele não pode ser analisado de maneira estanque ou isolada.

“O coronelismo é, sobretudo, um compromisso, uma troca de proveitos entre o poder público, progressivamente fortalecido, e a decadente influência social dos chefes locais, notadamente dos senhores de terra" (LEAL, 2012, p.44). Com esta definição introdutória, cabe salientar, segundo o precursor desse conceito, que essa relação recíproca de favores e de barganhas é ambientada durante a República Velha ou Primeira República, em um hiato histórico temporal entre a transição da monarquia para o federalismo republicano (1889) até o mandato presidencial inicial da Getúlio Vargas $(1930)^{11}$. Este período coincidiu com o período de relevante decadência econômica dos grandes latifundiários da agricultura que refletiu diretamente no enfraquecimento político dos coronéis em face dos seus rivais e dependentes.

O coronelismo foi uma alteração de forças dos mandões locais que a fim de manter seu poder e a sua influência local tiveram que ter a presença do Estado, que aumentava sua presença

\footnotetext{
${ }^{10}$ Victor Nunes Leal, em aula magna de início do curso de doutorado da IUPERJ, em março de 1980, revelou que José Murilo de Carvalho apresentou "compreensão muito mais profunda e correta do meu trabalho do que as têm a parecido em algumas apreciações de outros estudiosos do tema" (LEAL, 1980, p. 11)

${ }^{11}$ Com a proclamação da República, o Federalismo imposto pela Constituição Federal de 1891 fez surgir os estados federativos e a figura do governador de estado em substituição ao antigo presidente de província. Na prática, esse era escolhido pelo imperador, não possuía condições de construir suas bases, pois muitas vezes não era local e não tinha autonomia decisória - centralismo. Diferentemente, o governador republicano, além de ser escolhido pelo voto em eleição, era chefe da política local e tinha nos coronéis os oligarcas que o sustentava e o ajudava a manter o seu poder decisório e autônomo legal. Complementando sobre o termo, Giovani Corralo (2015) acredita que a rígida e dual separação de competências entre a União e os Estados no país por ocasião da implantação do Federalismo acabou por fortalecer as oligarquias regionais.
} 
graças ao federalismo, e que propiciou uma degradação crescente nos potentados locais. Segundo Carvalho (1984 e 1987), este sistema foi uma rede complexa fruto da interpolação de um fato político e de uma nova conjuntura econômica que permeou os níveis políticos do executivo e do legislativo nacional, estadual e regional em parceria com os coronéis e não exclusivamente o mandonismo local desse protagonista.

Agora qual seria a motivação, ou motivações, desta parceria, ou compromisso, entre as esferas pública e privada? Dentro do contexto do sistema coronelístico, o governo estadual garantiu para sua estrutura subordinada a manutenção do poder simbólico dos coronéis perante seus agregados, sua parentela e seus adversários, cedendo-lhes benesses financeiras para a sustentação municipal e o controle e o direito de indicação de diversos cargos públicos (delegados de polícia, escrivães, juízes, professores, secretários) e, em troca, recebia o compromisso de fidelidade eleitoral para seus candidatos ou aliados políticos - "política dos coronéis".

À União, a máquina estatal prestou apoio e aliança partidária a fim de manter a hegemonia da política nacional que, por sua vez, chancelava o reconhecimento de poder regional, a dominação e a de direção política e social do governador no seu espaço de atuação - "política dos governadores". Destaca-se que a política dos coronéis proporcionou um fortalecimento do poder estatal de modo mais efetivo do que a política dos governadores ao Estado. Neste diapasão, é mister ressaltar que a Federação possuía recursos e dispositivos legais (inclusive ingerência militar) para interferir diretamente nos governos, mas não caberia em função de uma negativa repercussão pública nacional.

Diferentemente, nas relações estaduais e municipais, bastava convencer um coronel da política local ou, em caso extremo, o emprego da violência se faria necessário, tendo em vista que a projeção e a importância do município em relação ao estado ou a União tinham menor amplitude e relevância política.

Com o passar do tempo, a lealdade política não mais se baseava no personalismo individual e na sensação de pertencimento de ser "gente" do coronel. O dinheiro ou bem material de troca tornaram-se instrumento de permuta desta fraude eleitoral. Estabeleceu-se um contrato tácito entre os integrantes do sistema dos coronéis. A compra dos votos tornou-se procedimento normal, tanto que Pang (id) fez alusão em sua obra a um caso empírico, ocorrido na primeira 
década do século $X X$, na Bahia, em que um oficial das Nações Unidas observou que muitos analfabetos jogavam na urna seus cupons de almoço, em vez da sua cédula de votação que lhes eram entregues juntas com o vale refeição pelo chefe local.

Convém destacar que a temática "coronelismo" no locus paranaense carece de mais fontes de pesquisa, pois, este autor, após relevante período de busca bibliográfica, encontrou as obras do pesquisador Alessandro Cavassin Alves (2006) e da pesquisadora Mônica Helena Harrich Silva Goulart (2004; 2008; 2015). Certamente há produções acadêmicas que tangenciaram de forma bem discreta e despretensiosa o conceito em questão, sem se aprofundar com o vigor necessário à demanda epistemológica do objeto de pesquisa desse breve artigo.

Outro aspecto relevante que carece de discussões mais detalhadas, que não será foco deste artigo, é o prazo de validade do coronelismo no contexto histórico. Há autores que partem da premissa da obra seminal de Victor Nunes Leal e deu seu maior defensor, José Murilo Carvalho, que o coronelismo é datado na história e teve sua vigência exclusivamente durante a Primeira República. No entanto, existem outras interpretações temporais, tais como Paul Cammack, que sustenta a existência mesmo durante o Estado Novo (1937-1945) e que, inclusive, se manteve, mesmo diante das tentativas do governo de Vargas para centralizar o poder em nível nacional. Ou na visão de Eul-Soo Pong de que os "novos" coronéis retornaram, entre as décadas de 1960 e 1970, sendo o elo dessas novas e plurais agremiações políticas com a população eleitoral, ressurgindo assim como "a nova elite partidária modificada" (PANG, id, p.62). Mas os "novos" coronéis continuam calcados nos seus fatores que os criaram. "Que importa que o "coronel" tenha passado a doutor? Ou que a fazenda tenha se transformado em fábrica.

\section{A INDISSOCIÁVEL RELAÇÃO POLÍTICA}

Essa conivência política marcada por interesses pessoais no sistema coronelista caracteriza o atual sistema brasileiro de comunicações que faz do apadrinhamento, do clientelismo, das relações familiais e do devir econômico predicados de destaque e de existência.

A evolução conceitual e histórica dessa relação sofre extensões interpretativas, a ponto de Santos \& Capparelli (2005) reinterpretarem a obra "Coronelismo, enxada e voto", de Victor Leal Nunes (1997) sob a ótica "Coronelismo, radiodifusão e voto". 
Os coronéis de outrora passam a integrar a política midiática do século XXI, fruto principalmente do surgimento da televisão e do rádio, da expansão do mercado impresso e dos espaços virtuais, meios eficazes de difusão ideológica e, principalmente, de expansão da hegemonia política e do poder simbólico que não se limita mais exclusivamente em seus currais eleitoreiros locais, mas em regiões longínquas, quiçá nas de seus adversários.

Os mandões modernos buscam se aferrar cada vez mais à radiodifusão e visam adquirir outras plataformas de comunicação a fim de concentrar a informação, bem como qualificar sua programação com intuito de reter e ampliar suas audiências, manter suas rendas publicitárias e difundir sua ideologia política.

A moeda de troca desse sistema comunicacional é o voto do eleitorado rural vinculado aos coronéis via motivação midiática em favor do político aliado, que, em contrapartida, facilita ao coronel eletrônico a outorga e, futuramente, a renovação das concessões do serviço de radiodifusão, além de apoio publicitário no orçamento da emissora "cedida". O "coronelismo eletrônico" torna-se presente, é a manutenção das elites políticas tradicionais, é a aliança entre o poder privado e os detentores das concessões radiofônicas, além de conceitualmente ser:

O sistema organizacional da recente estrutura brasileira de comunicações, baseado no compromisso recíproco entre poder nacional e poder local, configurando uma complexa rede de influências entre o poder público e o poder privado dos chefes locais, proprietários dos meios de comunicação. (SANTOS, 2008, p.2).

Abaixo no gráfico 1 , pode-se verificar quantitativamente a evidente relação entre os coronéis e a radiodifusão: 


\section{GRÁFICO 1: OUTORGAS DE TELEVISÃO CONTROLADAS POR POLÍTICOS}

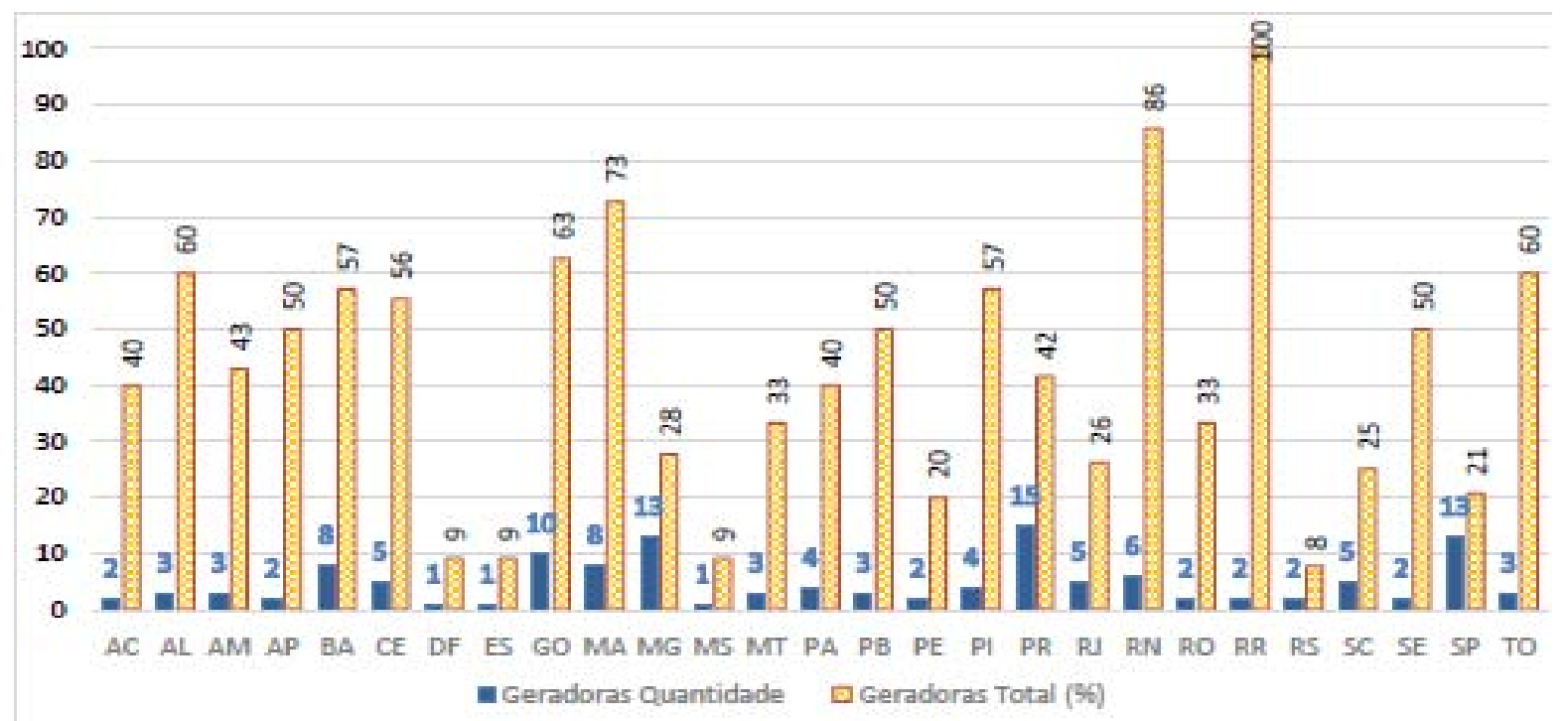

FONTE: Santos \& Capparelli (op.cit., p.95)

Nota-se, nesse gráfico, que $33,6 \%$ das geradoras de televisão encontram-se polarizadas nas mãos de políticos dos poderes executivo e legislativo ${ }^{12}$, grande evidência que os campos midiáticos e políticos caminham juntos.

Em levantamento quantitativo díspar, elaborado por James Görgen ${ }^{13}$ (2015), gráfico 2, que teve como objeto de análise figuras políticas sócias ou diretores de veículos de comunicação, o resultado corroborou com a análise anterior:

\footnotetext{
${ }^{12}$ A metodologia utilizada no gráfico 1, segundo os autores, foi "uma busca genérica na internet e em arquivos de jornais e revistas do país".

${ }^{13}$ Segundo a metodologia de James Görgen, "a propriedade de veículos de comunicação por parte de políticos com mandato pode ser maior que a apresentada. Optou-se por listar somente o controle direto ou a participação societária exercida por essas pessoas. Veículos exclusivamente em nome de familiares ou outros sócios não foram registrados. Da mesma forma, não foram computadas as propriedades de vereadores." O levantamento cruzou dados da Agência Nacional de Telecomunicações com a lista de prefeitos, governadores, deputados e senadores de todo o país para mapear quais deles são proprietários de veículo de comunicação
} 


\section{GRÁFICO 2: N DE POLÍTICOS SÓCIOS OU DIRETORES DE VEÍCULOS DE COMUNICAÇÃO POR ESTADO}

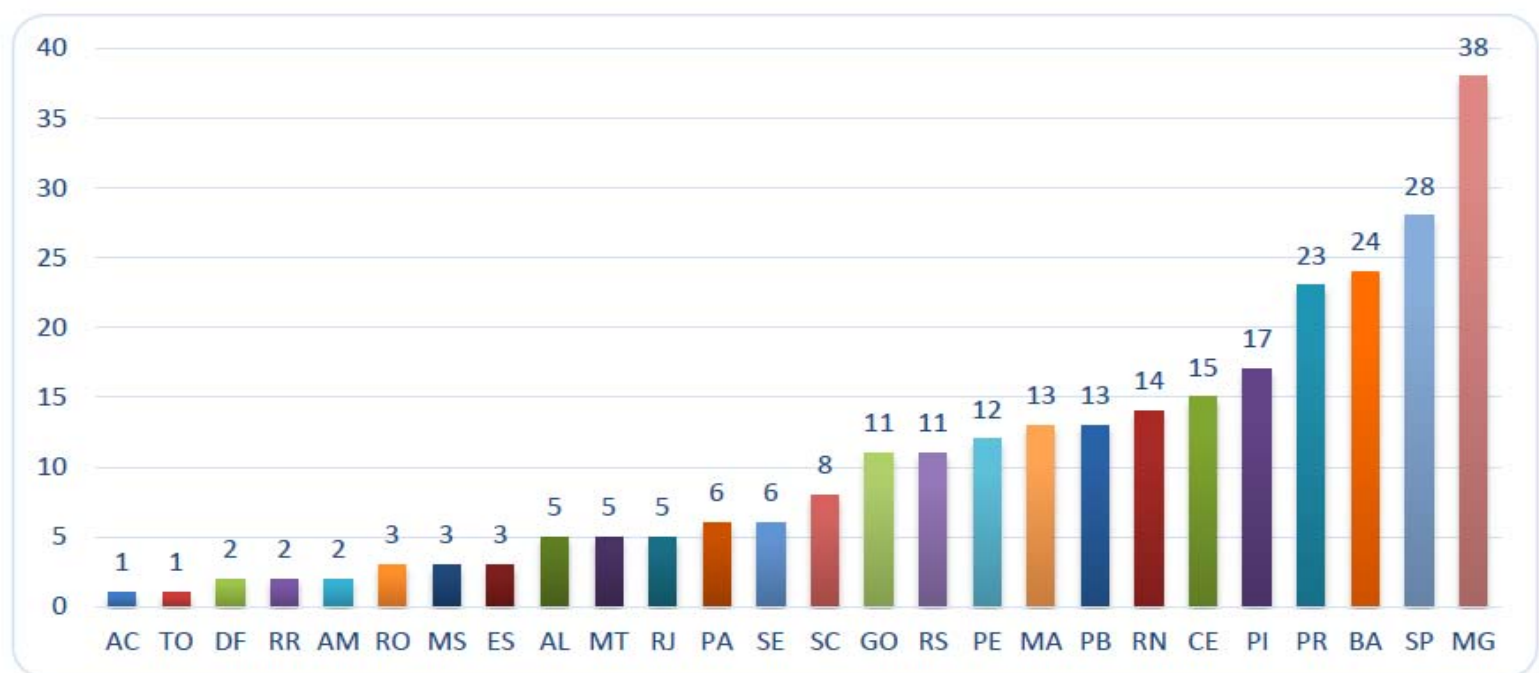

Fonte: Zapani e Pieroni (2016)

O poderio governamental e simbólico que políticos passaram a adquirir face ao controle de mídias massivas é notório - 271 políticos são sócios ou diretores de 324 veículos de comunicação no Brasil. No total desses veículos, aproximadamente, $7 \%$ pertence a senadores, $1 \%$ a governadores, $54 \%$ a prefeitos, $18 \%$ a deputados federais e $20 \%$ a deputados estaduais ${ }^{14}$.

No entanto, segundo o artigo 54 da CF88, deputados e senadores não poderão:

I - desde a expedição do diploma:

a) firmar ou manter contrato com pessoa jurídica de direito público, autarquia, empresa pública, sociedade de economia mista ou empresa concessionária de serviço público, salvo quando o contrato obedecer a cláusulas uniformes.

b) aceitar ou exercer cargo, função ou emprego remunerado, inclusive os de que sejam demissíveis ad nutum, nas entidades constantes da alínea anterior. (BRASIL, 1988, Art. 7ํㅜ)

Esta prática ilegal, e quase que institucionalizada, é confirmada pelo levantamento feito pelo DIAP (2014) constatando que a bancada dos meios de comunicação no Congresso Nacional, que inclui parlamentares em todos os partidos, embora tenha perdido em qualidade para a

${ }^{14}$ Dados referentes até ao mandato de dezembro de 2010. 
legislatura do mandato 2015-2019, continua contando com algo em torno de 60 parlamentares entre concessionários de rádio ou de televisão, mesmo sem a presença na próxima legislatura, por exemplo, de expoentes como José Sarney (PMDB-AP), Henrique Eduardo Alves (PMDB-RN) e Inocêncio Oliveira (PR-PE).

Apesar das perdas mencionadas, a bancada contará com a deputada Elcione Barbalho (PMDB-PA), reeleita; com Sarney Filho (PV-MA), reeleito; com Miro Teixeira (PROS), reeleito; com Arolde Oliveira (PSD-RJ), reeleito; com o senador Fernando Collor (PTB-AL), reeleito; com os senadores do PMDB Edison Lobão, Romero Jucá e Jader Barbalho, que tem mandato até 2019, além de contar com o novo senador Tasso Jereissati (PSDB-CE) e o novo deputado federal, ora ministro da saúde, Ricardo Barros (PP-PR).

Levantamento feito, após a confirmação do resultado das eleições de 2014, pelo jornal a Folha de São Paulo, aponta que "ao menos 55 concessões pelo país pertencem a políticos que vão tomar posse em 2015 que juntas, as rádios e televisões somam patrimônio de R\$ 8,3 milhões" (BACHTÖLD, 2014).

Os números destes recenseamentos são distintos, tendo em vista a metodologia de apuração utilizada, mas principalmente pela dificuldade de se descobrir quem são os reais proprietários destes veículos, pois diversos estão em nome de terceiros ou familiares.

A precisão nos números destas pesquisas é um quesito de menor importância se comparada com essa quase institucionalizada ilegalidade que é uma característica consolidada na política midiática brasileira e que sobrevive devido à pouca divulgação pelos veículos de comunicação à sociedade civil, à "passividade" das audiências, às alianças dos coronéis com a grande mídia comercial e às reinterpretações ordinárias e fisiológicas dos políticos sobre o assunto.

Corroborando essa parcialidade, o deputado Arolde de Oliveira (PSD-RJ) disse que "impedir sócios de emissoras de se candidatar seria discriminação. Se até analfabeto pode ser candidato, eu não posso por ter uma emissora?", bem como a declaração do deputado Gonzaga Patriota (PSB$\mathrm{PE}$ ), sócio em duas rádios, "que a internet mudou o cenário que esses meios costumavam ter. Hoje os meios de comunicação são democráticos". (BACHTÖLD, op. cit.)

O cenário político-midiático paranaense, no tocante à posse parlamentar de veículos de comunicação radiofônicos, não é diferente do contexto nacional. Referido óbice foi constatado, em menor proporção que na esfera nacional, em levantamento feito por este autor tomando por 
base o executivo e o legislativo estaduais e federais paranaenses eleitos para o mandato 20152019 que são proprietários (tabela 1) ou têm vínculos familiares diretos com sócios (tabela 2):

TABELA 1: PARLAMENTARES PARANAENSES, EM MANDATO, PROPRIETÁRIOS DE EMISSORAS

\begin{tabular}{c|c|c|c|c}
\hline Nome & Mandato & Partido & Emissora & Município \\
\hline Ricardo Barros & Dep. Federal & PP & Rádio Ingá AM & Maringá \\
\hline Artagão Junior & Dep. Estadual & PSB & Rádio Difusora & Guarapuava \\
\hline Luiz Claudio Romanelli & Dep. Estadual & PSB & Rádio Banda B & Curitiba \\
\hline Cantora Mara Lima & Dep. Estadual & PSDB & Rádio Louvor Eterno & Mandaguari \\
\hline Cida Borgheti & Vice-governadora & PP & Rádio Difusora AM & Maringá \\
\hline
\end{tabular}

TABELA 2: PARLAMENTARES PARANAENSES, EM MANDATO, QUE SÃO PARENTES DE PROPRIETÁRIOS DE EMISSORAS

\begin{tabular}{|c|c|c|c|c|}
\hline Nome & Mandato & Partido & Emissora & Município \\
\hline Sandro Alex ${ }^{15}$ & Dep. Federal & PSD & Rádio Central & Ponta Grossa \\
\hline Bernardo Carli ${ }^{16}$ & Dep. Estadual & PSDB & Rádio Guaicará & Guarapuava \\
\hline Luiz Carlos Martins ${ }^{17}$ & Dep. Estadual & PSD & Rádio Banda B & Curitiba \\
\hline Ratinho Júnior ${ }^{18}$ & Dep. Estadual & PSC & Grupo Massa & ver tabela 3 \\
\hline Maria Victória ${ }^{19}$ & Dep. Estadual & PP & Rádio Jornal AM & Maringá \\
\hline Artagão Junior ${ }^{20}$ & Dep. Estadual & PSB & Rádio Emissora Atalaia & Guarapuava \\
\hline Alexandre Curi ${ }^{21}$ & Dep. Estadual & PSB & Rádio Poema & Pitanga \\
\hline Anibelli Neto 22 & Dep. Estadual & PMDB & Cleveland FM & Clevelândia \\
\hline
\end{tabular}

15 Irmão do prefeito de Ponta Grossa, Marcelo Rangel, e filho de Nilson de Oliveira, proprietário também da Rádio Mundi FM, na mesma cidade.

${ }^{16}$ Irmão do ex-deputado Luiz Fernando Carli Filho, proprietário da Rádio Guaicará.

${ }^{17}$ Marido da proprietária da Rádio, Maria Aparecida da Silva Martins.

${ }^{18}$ Filho do proprietário da Rede Massa, Carlos Massa - o "Ratinho" (ver tabela 5 e gráfico 3)

${ }^{19}$ Filha do Dep. Federal Ricardo Barros e da Vice-governadora do Paraná, Cida Borgheti.

${ }^{20}$ Marido de Cleri Becher de Mattos Leão, proprietária da Rádio Emissora Atalaia

${ }^{21}$ Filho do ex-deputado Aníbal Khury Jr, proprietário da Rádio Poema, e genro de Luis Mussi, sócio da Rede Mercosul (ver tabela 3 e gráfico 3) 


\begin{tabular}{|c|c|c|c|c|}
\hline Plauto Miró ${ }^{23}$ & Dep. Estadual & DEM & Rádio Central & Ponta Grossa \\
\hline João Arruda 24 & Dep. Federal & PMDB & Grupo J. Malucelli & ver tabela 3 \\
\hline \multirow{2}{*}{ Dilceu Sperafico 25} & \multirow{2}{*}{ Dep. Federal } & \multirow{2}{*}{ PP } & Rádio Difusora AM/FM & Mal Cândido Rondon \\
\hline & & & Rede Integração AM & Toledo \\
\hline
\end{tabular}

Fonte: atualizado de Zapani e Pieroni (2016)

A Constituição Federal de 1988 determinou como novidades as atribuições do Congresso Nacional, que até então cabia exclusivamente ao Executivo, de apreciação dos atos de outorga e renovação de concessão, permissão e autorização para o serviço de radiodifusão sonora e de sons e imagens, fato que ocasionou um grande incremento nos trabalhos da $\mathrm{CCTCl}^{26}$.

Regredindo, em uma década, objetivando a consolidar a constância desta prática de autobenefício, que estabiliza a perpetuação do velho coronelismo e da adaptação para o coronelismo eletrônico, Lima (2006) demonstra que, em 2003, 15 dos 36 deputados membros da CCTCl eram concessionários de emissoras de rádio ou TV. Em 2004, a proporção aumentou para 15 deputados proprietários entre 29 integrantes.

Entretanto, a limitação imposta pelas nações internacionais em seus mercados radiofônicos comerciais ${ }^{27}$ visando restringir as propriedades cruzadas não corresponde com a realidade midiática brasileira que convive com a concentração de vários veículos impressos,

\footnotetext{
${ }^{22}$ Filho do ex-deputado estadual Antônio Anibelli, sócio da Rádio Cleveland.

${ }^{23}$ Tio do ex-deputado Luiz Fernando Carli Filho, proprietário da Rádio Guaicará

${ }^{24}$ Genro de Joel Malucelli, sócio emissoras do grupo Band (ver tabela 3 e gráfico 3)

${ }^{25}$ Irmão e marido dos proprietários das emissoras
}

${ }^{26}$ Essa comissão, uma das 20 permanentes da Câmara dos Deputados, é constituída por 42 deputados titulares e igual número de suplentes, atua como órgão técnico da Casa, apoiada por consultores legislativos e servidores administrativos. Curiosamente, diversos parlamentares federais são sócios ou associados de concessões de radiodifusão e compõem a $\mathrm{CCTCl}$, além disso, outorgam e renovam suas próprias concessões ou facilitam as de seus familiares, apadrinhados ou "laranjas". Podem ser inclusos nesta confluência de interesses: o deputado Sandro Alex, atual 1ำ vice-presidente desta comissão no mandato 2017 e exerceu a mesma função em 2015; Antônio Bulhões, suplente e deputado recordista de concessões radiofônicas no país (7 emissoras); Ratinho Júnior, ex-presidente da subcomissão permanente de radiodifusão e integrante titular até 2015, bem como foi 1o vice-presidente em 2008. Além da expansão da radiodifusão, especialmente com a instituição da radiodifusão comunitária, temas como a outorga e renovação da exploração de serviços de radiodifusão sonora e de sons e imagens, privatização das telecomunicações, a utilização de software livre, a inclusão digital e a criação das agências reguladoras fazem parte dos principais debates e deliberações da comissão.

${ }^{27}$ Sobre o conceito midiático de propriedade cruzada, ver Zapani (2015). 
audiovisuais e virtuais em nome de restritos grupos familiares e comerciais, consolidando o monopólio e a propriedade cruzada. Traços desta assertiva podem ser verificados após levantamento quantitativo feito com as principais famílias midiáticas do estado paranaense:

\section{TABELA 3: DADOS DAS PRINCIPAIS FAMÍLIAS PARANAENSES PROPRIETÁRIAS DE EMISSORAS}

\begin{tabular}{|c|c|c|c|}
\hline $\begin{array}{l}\text { Sobrenome } \\
\text { familiar }\end{array}$ & Grupo & Afiliada & $\begin{array}{c}\text { Municípios das emissoras/retransmissoras (RTV) }{ }^{28} \\
\text { (quantidade abrangida) }\end{array}$ \\
\hline Martinez & $\begin{array}{l}\text { Organização } \\
\text { OEME }\end{array}$ & CNT & $\begin{array}{l}\text { Londrina, Paranaguá, Guaratuba, General Carneiro, Terra } \\
\text { Rica, Lapa, Goiorê, São Mateus do Sul, Paranavaí, Cruz } \\
\text { Machado, Palmas. Bituruna, Matinhos, Loanda, Ponta } \\
\text { Grossa, Antônio Olinto e Curitiba (17) }\end{array}$ \\
\hline Solano & Solano & $\begin{array}{l}\text { Rede } \\
\text { Vida }\end{array}$ & Corbélia e Toledo (2) \\
\hline Petrelli & RIC & Record & $\begin{array}{l}\text { Toledo, Cascavel, Foz do Iguaçu, Santo Antônio da } \\
\text { Platina, Londrina, Cianorte, Campo Mourão, Cornélio } \\
\text { Procópio, Goiorê, Umuarama, Terra Rica, Apucarana, } \\
\text { Paranavaí, Jacarezinho, Ponta Grossa, Castro, } \\
\text { Guarapuava, Laranjeiras do Sul, Matinhos, Prudentópolis, } \\
\text { Paranaguá, Irati, Pitanga, Palmeira, São Mateus do Sul, } \\
\text { Colorado, Curitiba e Maringá (28) }\end{array}$ \\
\hline Massa & Massa & SBT & $\begin{array}{l}\text { Maringá, Apucarana, Loanda, Palmital, Roncador, Goiorê, } \\
\text { Pérola, Matinhos, Campo Mourão, Maringá, Paraíso do } \\
\text { Norte, Paranavaí, Guaíra, Umuarama, Colorado, Cruzeiro } \\
\text { do Oeste, Iporã, Pérola, Icaraíma, Curitiba, Pontal do } \\
\text { Paraná, Paranaguá, Irati, Guarapuava, Guaratuba, União } \\
\text { da Vitória, Ponta Grossa, Prudentópolis, Morretes, São } \\
\text { Mateus do Sul, São José dos Pinhais, Foz do Iguaçu, Assis } \\
\text { Chateaubriand, Francisco Beltrão, Mal. Cândido Rondon, } \\
\text { Santa Helena, Palotina, Itaipulândia, Medianeira, São } \\
\text { Miguel do Iguaçu, Formosa do Oeste, Wenceslau Braz, } \\
\text { Santo Antônio da Platina, Jacarezinho, Bandeirantes, } \\
\text { Porecatu e Campo Largo (47) }\end{array}$ \\
\hline Maluceli & J. Maluceli & Band & $\begin{array}{l}\text { Maringá, Curitiba, Ponta Grossa, Guaratuba, Paranaguá, } \\
\text { Piraquara, Matinhos, Pontal do Paraná, Rio Branco do } \\
\text { Sul, Castro e Paranavaí (10) }\end{array}$ \\
\hline Andrade Vieira & Andrade Vieira & - & Londrina \\
\hline Lemanski & GRPCOM & Globo & $\begin{array}{l}\text { Curitiba, Maringá, Campo Mourão, Ivaiporã, Tupãssi, } \\
\text { Nova Cantu, Ponta Grossa, Tibagi, Ventania, Palmeira, } \\
\text { União da Vitória, Turvo, Siqueira Campos, Castro, Foz do } \\
\text { Iguaçu, Francisco Beltrão, Pato Branco, Enéas Marques, } \\
\text { Planalto, Paranavaí, Altônia, Cianorte, Nova Esperança, }\end{array}$ \\
\hline
\end{tabular}

${ }^{28}$ Constam nesta tabela a localização dos municípios-sede das emissoras de rádio AM/FM de TV, bem como das retransmissoras (RTV) que são serviços que "se destina a retransmitir, de forma simultânea ou não, os sinais de estação geradora de televisão, para a recepção livre e gratuita pelo público em geral, e tem por finalidade possibilitar que os sinais das estações geradoras sejam recebidos em locais por eles não atingidos diretamente ou atingidos em condições técnicas inadequadas. " (MINISTÉRIO DAS COMUNICAÇÕES, 2017) 


\begin{tabular}{c|c|c|l}
\hline & & $\begin{array}{l}\text { Terra Rica, Umuarama, Cidade Gaúcha, Guaíra, Goiorê, } \\
\text { Alto Paraná, Loanda, Cascavel, Mal Cândido Rondon, Céu } \\
\text { Azul, Paranaguá, Santo Antônio da Platina, Guaratuba, } \\
\text { Londrina, Lapa, Matinhos, Pontal do Paraná, Arapongas, } \\
\text { Cornélio Procópio, Jacarezinho e Piraquara (44) }\end{array}$ \\
\hline Tezelli & Tezelli & - & $\begin{array}{l}\text { Campo Mourão, Goiorê, Cianorte, Guarapuava, } \\
\text { Paranacity, Telêmaco Borba e Brazilândia do Sul (7) }\end{array}$ \\
\hline Mussi & Seleski & - & $\begin{array}{l}\text { Marmeleiro, Francisco Beltrão, Itapejara do Oeste, } \\
\text { Realeza e São João (5) }\end{array}$ \\
\hline Mussi & Mercos & $\begin{array}{l}\text { Astorga, Pontal do Paraná, Cianorte, Ivaiporã, Guaratuba, } \\
\text { Pato Branco, Cascavel, Castro, Paranaguá, Ponta Grossa, } \\
\text { Matinhos, Londrina, Guaíra, Curitiba, Campo Largo, } \\
\text { Morretes, Toledo, União da Vitória, Irati, Prudentópolis, } \\
\text { Guarapuava, São Mateus do Sul e Icaraíma (23) }\end{array}$ \\
\hline Bulbinotti & Tarobá & Band & $\begin{array}{l}\text { Cascavel, Cianorte, Umuarama, Céu Azul, Pato Branco, } \\
\text { Mal Cândido Rondon, Dois Vizinhos, Palotina, Foz do } \\
\text { Iguaçu, Paranavaí, Assis Chateaubriand, Laranjeiras do } \\
\text { Sul, Guarapuava, Toledo, Medianeira, Itaipulândia, Santa } \\
\text { Helena e Londrina (18) }\end{array}$ \\
\hline Canet & Balbinotti & - & $\begin{array}{l}\text { São João do Ivaí, Engenheiro Beltrão, Barbosa Ferraz e } \\
\text { Sarandi (4) }\end{array}$ \\
\hline
\end{tabular}

FONTE: Ministério das Comunicações (2017)

GRÁFICO 3: LEVANTAMENTO QUANTITATIVO DE VEÍCULOS DE COMUNICAÇÃO DE PROPRIEDADE DE FAMÍLIAS PARANAENSES,

\begin{tabular}{|c|c|c|}
\hline CANNET & $100 \times$ & \\
\hline BALBINOTTI & 5 & \\
\hline MUFATTO & 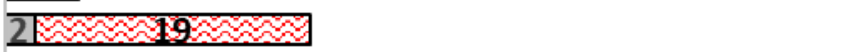 & 日RADIO \\
\hline MUSSI & 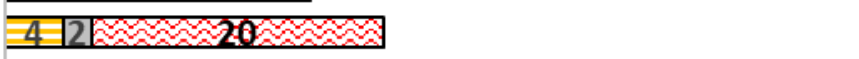 & \\
\hline SELESKI & 6 & 口TV \\
\hline TEZELLI & 8 & \\
\hline LEMANSKI & 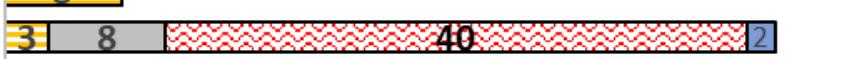 & QRTV \\
\hline ANDRADE VIEIRA & \begin{tabular}{l|l}
2 & 3 \\
2
\end{tabular} & חORNAI \\
\hline MALUCELLI & 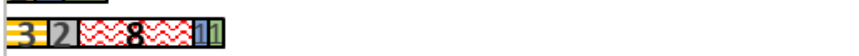 & UJURINAL \\
\hline MASSA & 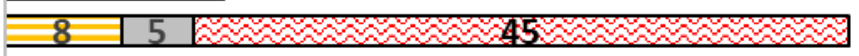 & $П \mathrm{PORTAI}$ \\
\hline PETRELLI & 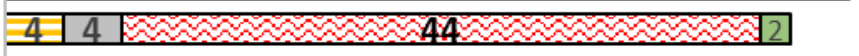 & \\
\hline SOLANO & ( & \\
\hline MARTINEZ & 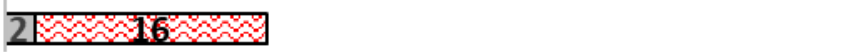 & \\
\hline
\end{tabular}

Fonte: Görgen (2015), Ministério das Comunicações (2017) e sites das emissoras dos grupos 
Analisando de forma panorâmica as tabelas e gráfico deste item pode-se concluir que o mercado radiofônico paranaense é uma réplica do seu análogo nacional no tocante à propriedade das emissoras de sons e imagens (TV). Evidencia-se que somente foram quantificadas as emissoras que realmente são de posse daquelas famílias, desconsiderando as que estão em nome de terceiros, mesmo sabendo, segundo o domínio público, que são de propriedade de integrantes das famílias pesquisadas.

\section{CONSIDERAÇÕES FINAIS}

O coronelismo no Paraná, objeto de pesquisa deste autor, é um tema que carece de aprofundamento teórico, principalmente no tocante à sua validade temporal contemporânea, bem como à sua inserção em outro campo do conhecimento (Comunicação) - Coronelismo Eletrônico. Este artigo partiu da hipótese de sua confirmação e visou demonstrar a relevância do poder midiático na construção hegemônica de grupos dominantes de poder que, baseados em relações familiais, apadrinhamentos e desregulação do campo comunicacional, se solidificam e se perpetuam em posições decisórias no campo político paranaense e na apropriação da res publica.

\section{REFERÊNCIAS}

BRASIL. Lei de no 602, 19 de setembro de 1850. Nova organização da Guarda Nacional do Império. Coleção das leis do Império do Brasil de 1850. Tomo XI - Parte I. Rio de Janeiro: Tipografia Nacional, 1873.

Disponível

em: <http://www2.camara.leg.br/atividadelegislativa/legislacao/publicacoes/doimperio/colecao 3.html>. Acesso em: 2 abr. 2016.

. Constituição (1931). Constituição: República Federativa do Brasil. Rio de Janeiro, RJ: Senado Federal, 1831.

. Constituição (1988). Constituição: República Federativa do Brasil. Rio de Janeiro, RJ: Senado Federal, 1988. 
BACHTÖLD, Felipe. Congressistas eleitos têm 55 concessões. Jornal Folha de S.Paulo, 2014. Disponível em: <http://www1.folha.uol.com.br/poder/2014/12/1561839congressistas-eleitos-tem-55- concessoes.shtml>. Acesso em: 22 jul. 15

CAMMACK, Paul. O "Coronelismo" e o "Compromisso Coronelista": Uma Crítica. Cadernos do Departamento de Ciência Política, no 5, Belo Horizonte: UFMG, 1979, p. 1-20.

CARONE, Edgar. Coronelismo: definição histórica e bibliográfica. Revista de Administração de Emprêsas, Rio de Janeiro, v.11, n. 3, p.85-92, 1971.

CARVALHO, José Murilo. Coronelismo. In: Dicionário Histórico-Biográfico Brasileiro. Rio de Janeiro: CPDOC/Fundação Getúlio Vargas, Forense Universitária, 1984.

CARVALHO, José Murilo; SILVA, Eduardo. Entre enxada e o voto. In: Acervo: Revista do Arquivo Nacional. v.2. n.1.Rio de Janeiro: Arquivo Nacional, 1987, p.23-28.

CASTRO, Jeanne. Milícia Cidadã: a Guarda Nacional de 1831 a 1850. São Paulo: Companhia Editora Nacional, 197

CAVASSIN ALVES, Alessandro. Clientelismo eleitoral e coronelismo político: estudo de um pequeno município paranaense. In: Partido e eleições no Paraná. Edição Comemorativa: 60 anos. CODATO, Adriano; SANTOS, Fernando (org.). Curitiba: Tribunal Regional Eleitoral, 2006, p.147-169

CHAUL, Nasr. Coronelismo em Goiás: estudos de casos e famílias. Goiânia: Editora Kelps, 1998.

CORRALO, Giovani. O poder municipal na federação brasileira: reflexão sobre a autonomia municipal e o federalismo. Revista História: Debates e Tendências. Universidade de Passo Fundo, Rio Grande do Sul, v.15, n.1, jan./jun.2015, p.128-139CORRÊA, Alessandro. Por que a maioria dos municípios brasileiros não se sustenta? BBC Brasil. Disponível em: http://www.bbc.com/portuguese/noticias/2012/09/120912 brasil gestao fiscal ac.shtml. Acesso em: 23 out.2016.

COSENTINO, Francisco. Construindo o Estado do Brasil: instituições, poderes locais e poderes centrais. p. 536-545. In: O Brasil colonial: volume 1 (1443-1580). FRAGOSO, João; GOUVEIA, Maria (Org.). Rio de Janeiro: Civilização Brasileira, 2015. 
GÖRGEN, James. Donos da mídia. Disponível em: <http://donosdamidia.com.br>. Acesso em: 3 abr. 2015.

GOULART, Mônica. O poder local no Paraná da República Velha 1880-1930. Curitiba, 2004. 232 f. Dissertação (Mestrado em Sociologia) - Setor de Ciências Humanas, Letras e Artes, Universidade Federal do Paraná.

. Classe dominante e jogo político na Assembleia Legislativa Paranaense (1889-1930). Curitiba, 2008. 609 f. Tese (Doutorado em Sociologia) - Setor de Ciências Humanas, Letras e Artes, Universidade Federal do Paraná.

. O poder local e o coronelismo no Paraná. Revista do Núcleo de Estudos Paranaense. v.1,n.1. Curitiba: UFPR, 2015, p.15-39.

JANOTTI, Maria. O coronelismo: uma política de compromissos. São Paulo: Brasiliense, 1981.

JUNQUEIRA, Messias. Justificativa e anteprojeto de lei de terras. São Paulo: Empresa Gráfica Revista dos Tribunais Ltda., 1942.

LEAL, Victor Nunes. O Coronelismo e o Coronelismo de cada um. Dados - Revista de Ciências Sociais, vol. 23, nำ1, 1980, p.11-14.

. Coronelismo, enxada e voto: o município e o regime representativo no Brasil. 7ạ edição. São Paulo: Companhia das Letras, 2012.

LIMA, Ruy Cirne. Pequena história territorial do Brasil: sesmarias e terras devolutas. 4. ed. Brasília: ESAF, 1988.

LIMA, Venício. Mídia: crise política e poder no Brasil. São Paulo: Perseu Abramo, 2006.

MERÊA, Paulo. A solução tradicional da colonização do Brasil. DIAS, Carlos Malheiro (Dir.). História da colonização portuguesa no Brasil. v. 3, Porto: Litografia Nacional, 1924. 
MINISTÉRIO DAS COMUNICAÇÕES. RTV - Apresentação. Disponível em: http://www2.mcti.gov.br/index.php/espaco-do-radiodifusor/rtv. Acesso em: 22 abr. 2017.

OLIVEIRA, Ricardo Costa de. Na teia do nepotismo - sociologia política das relações de parentesco e poder político no Paraná e no Brasil. Curitiba: Insight, 2012.

PANG, Eul-Soo. Coronelismo e oligarquias: 1889-1934 - A Bahia na primeira República Brasileira. Rio de Janeiro: Civilização Brasileira, 1979.

RÊGO, André Heráclito. Família e coronelismo no Brasil: uma história de poder. São Paulo: Girafa, 2008.

SANTOS, Suzy. Relações incestuosas: mercado global, empresariado nacional de radiodifusão e líderes políticos/regionais. In: XXXI CONGRESSO BRASILEIRO DE ESTUDOS INTERDISCIPLINARES DE COMUNICAÇÃO, Natal, 2008. Anais do VIII Encontro dos Núcleos de Pesquisa em Comunicação - NP Políticas e Estratégias de Comunicação, 2008, p.1-16

SANTOS, Suzy; CAPPARELLI, Sérgio. Coronelismo, radiodifusão e voto: a nova face de um conceito. In: BRITTOS, Valério; BOLAÑO, César (org.). Rede Globo: 40 anos de poder e hegemonia. São Paulo: Paulus, 2005, p. 77-101.

VIANNA, Francisco de Oliveira. Evolução do povo brasileiro. São Paulo; Cia. Ed. Nacional, 1933.

ZAPANI. André Kron. Capitanias midiáticas neopentecostais: da formação à busca pelo poder hegemônico. 2011, 114p. Dissertação - Universidade Tuiuti do Paraná. Curitiba, 2011.

- Os coronéis e as propriedades midiáticas: uma análise da concentração do poder midiático nacional. In: VII Encontro de pesquisadores em Comunicação, 2015, Curitiba. ANAIS DO VII ENPECOM. Curitiba: UFPR, 2015. p. 1014-1028.

ZAPANI, André Kron; PIERONI, Geraldo. Coronelismo eletrônico: a concentração do poder midiático nacional e no Paraná. Ação Midiática - Estudos em Comunicação, Sociedade e Cultura, v. 1, p. 241-266, 2016. 